\title{
INVESTIGATION FOR YOUNG ADULTS INTEREST IN HEALTH
}

\author{
Andrea Szoboszlai \\ szoboszlai.andrea@ppk.elte.hu \\ Eötvös Loránd University, Hungary
}

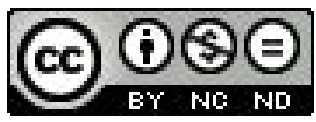

\begin{abstract}
Young adulthood is a critical period because it is the time when young people begin to live on their own, and adopt health behaviours which can influence their lifestyle and health status. In social practice there are many community belongings and community-based support systems and programs in health, which aim to increase young adults' health literacy and offer learning possibilities and support services.

The study focuses on the education and the literacy as determinants of health, several fields of health education and health promotion related to young adults, elements and determinants of health culture, the links between health and learning, adults' interest and claims related to learning process, methods, topics.

In my research I made a survey of learning methods and contents with the help of the analysis of the scientific literature and by questionnaires. I examined young adults' (18 to 30) concepts of health and healthy lifestyle, motivations, forms of communication, learning methods and participation in community platforms of health. We use the results of this research to improve programs that support young people's learning activities for health.

Key words: health literacy, health culture, young adults, concepts of health and healthy lifestyle, motivations, forms of communication, learning methods.
\end{abstract}

\section{THEORETICAL BACKGROUND OF THE RESEARCH}

The World Health Organization's (WHO) definition of health promotion is: "Health promotion is the process of enabling people to increase control over, and to improve, their health" (WHO, 1986, p. 1). In this approach, adult education plays an important role; however, it relies more on support from organisations and communities rather than on individual work. In the late 1990s UNESCO defined health education as a part of health promotion (UNESCO Institute for Education, 1999). "Health education is not only concerned with the communication of information, but also with fostering the motivation, skills and confidence (self-efficacy) necessary to take action to improve health" (WHO, 1998, p. 4). According to WHO the main point of health education is not only knowledge mediation, but also improvement of skills and self-confidence.

The starting point in health promotion is the WHO definition of health (1946). Accordingly, "health is a state of complete physical, mental and social well-being and not merely the absence of disease or infirmity" (WHO, 1946, p. 2). This approach is called "positive health term", as being healthy means to possess so- 
mething and not the lack of something (Meleg, 2002, p. 12). In this research I follow the WHO's health definition. The emerging of the term "ecological health" was a critical progress. It completes the WHO health definition; accordingly, health is a state of balance between an individual and their environment, which focuses equally on natural and social environment, and in which role of society are appreciating better and better (Pikó, 2006). Veronika Szarvasné Mátó and Zsuzsanna Benkó examined college students' concepts of health in one of their research, and they concluded that there are mistakes and misinterpretations in students' understanding of health, and furthermore, students focus not only on the physical, but also the mental health dimension (Szarvasné Mátó, \& Benkó, 2006)

In the first point of the research I examine the term of health according to criteria such as what kind of health's components are important for young adults, what they think about the value of health in their own life, how they assess their own health status, where in they took account of protection of their own health in the course of career choice. Subjective opinions on health are reflected in the laic understanding of health, which plays a notable role in determining health behaviour and coming to a decision of lifestyle. The assessment of own health status passes by the laic understanding of health, thus self-perceived health can play a part in shaping health behaviour and lifestyle (Pikó, 2006).

Decisions concerning lifestyle can depend on what living conditions lead us to behaviour changes, how we are informed, and what kind of information, knowledge we have. According to Sándor Kormos health education is science-based knowledge mediation and behaviour shaping, summarily this is formation of identity which aims at health (Kormos, 1980). To have information is not enough to change lifestyle and health status. Nowadays the term of health literacy comes more and more to the front, which Ilona S. Kickbusch defines as a result of health education (Kickbusch, 2001). WHO's health literacy definition includes knowledge to take action to improve health, and implies "the cognitive and social skills, which determine the motivation and ability of individuals to gain access to, understand and use information in ways which promote and maintain good health" (WHO, 1998, p. 10).

Instead of the expression "health education" Attila Elekes frequently uses the term "education on healthy lifestyle". It refers to the elements of lifestyle - health culture is one component - that can be acquired (the components of health culture are health and lifestyle). Relationship between lifestyle and health denotes that an individual can regulate his or her health status through their lifestyle, respectively satisfy health needs by their lifestyle, further health status reacts lifestyle (Elekes, 2006). In my research I investigate the characteristics of knowledge acquirement, learning claims, participation in several trainings, learning agencies and programs.

As in health education fostering the motivation plays an important role, it is worth to review the motives. Accordingly, the third element of the research is motivation. One of the motives is that edutainment (it means education in entertainment or entertainment in education) can be experience-based, what is 
supported by the thought that flow among others motivates to learn (Csíkszentmihályi, 1998; Feketéné Szakos, 2010). Edutainment can play a part in health education. In this research I examine what young adults think about the importance of experience in learning. My earlier research's results point out that adult learners are motivated in knowledge acquirement by such motives as protection of their own health, curiosity, thirst for knowledge and being well-informed. Among motives that affect behaviour there are life conditions, in which we have to take care of our health increasingly, e.g. appearance of diseases, having children, change of work or workplace (Szoboszlai, 2011). These categories of motives helped me to compose potential answers to the questions related to motivation in the course of preparation of present research.

For defining of young adults I use in the matter of age of the examined persons and rate in to this category between the ages of 18-30 age-groups. I rely on conceptualization of age by Franz Pöggeler when I use this term, it says that a young adult is between 18 and 30 years old (Zrinszky, 1996).

\section{THE AIM AND THE QUESTIONS OF THE RESEARCH}

The aim of this research as a greater comparative research's first phase is to examine interest related to health of young adults of 18-30, who have intermediate or superlative qualification. In the research I took the following questions into consideration:

- What concepts related to health and healthy lifestyle characterise young adults of 18-30, who study or earlier studied at Loránd Eötvös University, Faculty of Education and Psychology, as well as young adults of 18-30, who participate in the Faculty's programs, e.g. sport programs?

- What do they think about value of health in their own life?

- What kind of topics related to health are they interested in?

- How do they acquire knowledge, and what learning forms do they prefer regarding health?

\section{THE METHODOLOGY}

Research was carried out at Loránd Eötvös University, Faculty of Education and Psychology (ELTE PPK) in 2012. I investigated young adults of 18-30 by questionnaires. The research was anonymous. Altogether 120 filled in questionnaires accumulated. I received 111 correctly filled in questionnaires. The majority of the respondents study or earlier studied at Loránd Eötvös University, Faculty of Education and Psychology. In the sample $(\mathrm{n}=111)$ there are 25 men $(22.52 \%)$ and 86 women $(77.48 \%)$. The average age of the respondents is: 22.42 years. Repartition of the marital status: 20 single men (18.02\%), 68 single women (61.26\%), 21 companions (18.92\%), 2 married (1.8\%). According to the qualification 53 respondents $(47.75 \%)$ have intermediate qualification, 58 respondents $(52.25 \%)$ have superlative qualification. 
Tab. 1. Introduction of the examined sample.

\begin{tabular}{|l|r|r|}
\hline Degree programs/professions & Persons & \multicolumn{1}{c|}{$\%$} \\
\hline Andragogy degree program & 11 & $9.91 \%$ \\
\hline Youth worker degree program & 4 & $3.6 \%$ \\
\hline Intercultural pedagogy and psychology degree program & 17 & $15.32 \%$ \\
\hline Conductor-instructor degree program & 2 & $1.8 \%$ \\
\hline Pedagogy degree program & 6 & $5.41 \%$ \\
\hline Psychology degree program & 16 & $14.41 \%$ \\
\hline $\begin{array}{l}\text { Recreation organisation and health promotion degree } \\
\text { program }\end{array}$ & 12 & $10.81 \%$ \\
\hline Sport organiser degree program & 8 & $7.21 \%$ \\
\hline Teacher training degree program & 11 & $9.91 \%$ \\
\hline Other degree program & 6 & $5.41 \%$ \\
\hline „Unknown” degree program & 9 & $8.11 \%$ \\
\hline Workers on the labour market & 9 & $8.11 \%$ \\
\hline Summary & 111 & $100 \%$ \\
\hline
\end{tabular}

Source: Author.

11 students participate in teacher training degree programs. They attend the following degree programs: English, game and recreation organiser teacher; English-Hungarian teacher; music teacher; Hungarian-philosophical teacher; mathematics-child protection teacher; German, game- and recreation organiser teacher; Romanistics-Spanish teacher and history teacher. Among students in other degree programs there are those who study painting, geology, meteorology, international administration and social work. Among the categories I use the expression of "»unknown" degree program", because 9 students did not mention what they study. The respondents who are on the labour market work as an insurance agent, a manufacturing organiser, a clerk, a non-profit manager, a training organiser, a psychologist and a service desk agent. Participants in the latter category - workers on the labour market - do not study at present. According to living quarters of respondents: 76 young adults $(68.47 \%)$ live in Budapest, 35 persons $(31.53 \%)$ lodge in the centre of county seat, in a town or in a village.

The research focuses on young adults' concepts of health; apprehension of health as a value; self-perceived health; importance of health in career choice; respectively characteristics of knowledge acquirement and participation in trainings and programs according to aspect of general education related to health; learning motivations; interest and claims related to learning process, methods, topics.

\section{THE RESULTS OF THE RESEARCH}

In the investigated young adults $(\mathrm{n}=111) 9$ people $(8.11 \%)$ perceive their health status excellent, 32 people $(28.83 \%)$ assess it very good, 55 people $(49.55 \%)$ think "goodish", 13 people feel $(11.71 \%)$ rather wrong and 2 people $(1.80 \%)$ esteem it very wrong in latter time. A small number of respondents assess their health 
status excellent, therefore presumably the majority of persons need to learn how to improve their health.

In the following task respondents $(n=111)$ had to assess on a scale $(1-10)$ health as value in their life. The value " 10 " meant health is the greatest value, and according to the value " 1 " health is not of any value. 3 people $(2.7 \%)$ chose value " 4 ", 1 people $(0.9 \%)$ signed value " 5 ", 5 people $(4.5 \%)$ marked value "6", 17 people (15.32\%) assigned value " 7 ", 29 people (26.13\%) asserted value " 8 ", 24 people $(21.62 \%)$ stated value " 9 " and 32 people $(28.83 \%)$ mentioned value " 10 " in the questionnaire. A large number of respondents marked the highest values " 8 ", " 9 ", or " 10 ". In the matter of health promotion the base of learning regarding health is that everyone thinks health is a value.

In the third question respondents $(n=109)$ could choose several statements expressing which components belong to health according to their opinion. There where the following statements in the questionnaire:

a) to have all parts of my body at operable state,

b) to be spiritually balanced,

c) to be with other people in accordance in my social connections,

d) to be in peace with myself,

e) to be worth high age,

f) to have a job,

g) to eat "right" food,

h) to never smoke,

i) to drink alcohol in reason or none.

102 persons (93.58\%) chose the "a" answer, 102 persons (93.58\%) marked „ $\mathrm{b}$ ", 80 persons $(73.39 \%)$ selected " $\mathrm{c}$ ", 88 persons $(80.73 \%)$ responded „ $\mathrm{d}$ " in this task. 45 adults $(41.28 \%)$ chose „e $\mathrm{e}^{\prime \prime}, 46$ adults $(42.20 \%)$ went for „f $\mathrm{f}^{\prime \prime}, 76$ adults $(69.72 \%)$ mentioned "g", 58 adults (53.21\%) checked "h" and 49 adults (44.95\%) chose ,i". The majority of respondents emphasised components regarding the physical and the mental health; however, a large number of people marked social relations connected with social health.

In the next question I asked respondents $(n=111)$ to sign on a scale $(1-10)$, wherein they thought it is important to choose such profession, which can cause damage their health least of all. The value "10" meant this sight was the most important, and the value "1" 1 "represented it was unimportant. 8 people $(7.21 \%)$ assigned the value "1" 16 people $(5.41 \%)$ chose the value "2", 7 people $(6.31 \%)$ mentioned the value ${ }^{\prime} 3$,, 7 people $(6.31 \%)$ asserted the value $, 4 ", 10$ people $(9.01 \%)$ signed the value, 5 " , 9 people $(8.11 \%)$ marked the value " $6 ", 16$ people $(14.41 \%)$ answered the value " $7 ", 21$ people (18.91\%) checked the value " 8 ", 15 people (13.51\%) labelled the value " 9 " and 12 people $(10.81 \%)$ stated the value "10" in the questionnaire.

They could explain their answer. $72(n=72)$ young adults commented on a reason of their choice. Basing on their answers I shaped 9 categories:

a) health was an important aspect,

b) health was no aspect,

c) it was primary to choose such a profession that gratifies and does not cause damage, 
d) health was more important aspect than salary,

e) by choice an appropriate field of interest health was aspect less,

f) salary was more important aspect than health,

g) if profession is harmful too, a groove at work is more important,

h) experience related to health was relevant factor,

i) other.

26 persons (36.11\%) agreed with ",a”, according to 19 persons $(26.39 \%)$,"health was no aspect" , 4 persons (5.56\%) chose „,c , 4 persons $(5.56 \%)$ selected „ $\mathrm{d}^{\prime \prime}, 8$ persons $(11.11 \%)$ decided on ", $\mathrm{e}^{\prime \prime} .3$ persons $(4.17 \%)$ wrote ", $\mathrm{f}^{\prime \prime}, 4$ persons $(5.56 \%)$ mentioned "g", 2 persons (2.78\%) went for ",h" and 2 persons $(2.78 \%)$ chose "other" as the answer. The "other" category concerned the following answers: „it depends where someone works, but many times he/ she must choose out of necessity" and "there is no such job that could be healthy". A large number of people took health into account in the course of their career choice. For that very reason workplaces should ensure conditions that support protection of health (e.g. through health promotion programs at a workplace).

78 people, i.e. $70.27 \%$ of the young adults $(n=111)$ answered that they would participate in a sort of learning process related to health, and 33 persons $(29.73 \%)$ asserted that they would not participate. Those who answered "yes" ( $=78)$, in the next question could mark a few of 7 learning forms according to which they would prefer. The statements were:

a) presentation about the topic,

b) talking to a small group,

c) solving of individual tasks,

d) learning through multimedia or internet,

e) roleplay,

f) other playful method,

g) other.

34 people $(43.60 \%)$ would listen to presentation, 44 people $(56.41 \%)$ would participate in talking to a small group, 24 people $(30.77 \%)$ prefer solving of individual tasks, 16 people $(20.51 \%)$ would take part in learning through multimedia or internet, 12 people $(15.39 \%)$ would try roleplay, 26 people $(33.33 \%)$ would attend an other playful method (e.g. training) and 4 people $(5.13 \%)$ would stand in other learning form. The majority of respondents would participate in a sort of learning process related to health. Mainly they are interested in talking to a small group, presentation, or other playful methods. It would be necessary to plan for such learning programs young adults, which are founded on communal learning, knowledge acquirement and activity.

Respondents could express what kind of topics in a training they would deal with. I grouped the answers into 9 categories:
a) nutrition,
b) topics related to body, body sense,
c) exercise, sport,
d) mental health, coping with stress,
e) maleficent customs and their affect, 
f) health protection, lifestyle, consultancy,

g) other topics in general training,

h) vocational interest,

i) being open-minded.

Among respondents $(n=67) 36$ persons $(53.73 \%)$ are interested in nutrition, 3 persons $(4.48 \%)$ like topics related to body, body sense, 19 persons $(28.36 \%)$ prefer exercise, sport, 17 persons $(25.37 \%)$ would deal with topic of mental health, coping with stress. 2 persons $(2.98 \%)$ are concerned with maleficent customs and their affect, 14 persons $(20.90 \%)$ are interested in health protection, lifestyle, consultancy, 6 persons $(8.95 \%)$ would deal with other topics in general training (e.g. rehabilitation, relaxation, prejudices), 2 persons $(2.98 \%)$ have vocational interest and 2 persons $(2.98 \%)$ are open-minded. The majority of young adults are interested primarily in topics related to physical and mental health, such as nutrition, exercise, sport, as well as mental health and coping with stress.

I also asked young people $(n=111)$, what activities and programs they participate actively in. They could chose from several answers:

a) measurement, consultancy,

b) sport program, sport competition,

c) informative presentation,

d) fitness display,

e) product tester (biofood, healthy food),

f) blooddonation as a voluntary blood donor,

g) other,

h) none.

Among the examined people 16 respondents (14.41\%) participate in measurement, consultancy, 61 respondents $(54.96 \%)$ are active in a sport program or competition, 20 respondents (18.02\%) listen to some informative presentations, 17 respondents (15.32\%) attend fitness display, 11 respondents $(9.91 \%)$ test products, 15 respondents (13.51\%) donate blood as voluntary blood donors, 3 respondents $(2.70 \%)$ take part in other program (e.g. family days, coaching). 25 respondents $(22.52 \%)$ chose the "none" answer. The following numbers characterise the frequency of participation $(\mathrm{n}=111)$ : 23 people $(20.72 \%)$ never, 2 people $(1.80 \%)$ once a day, 8 people $(7.21 \%)$ several times weekly, 23 people $(20.72 \%)$ a few times a month and 55 people $(49.55 \%)$ once a year. A large number of people participate in programs regarding health, accordingly, presumably this group are retractable in further health promotion programs.

In the next question I examined with what communication tools young adults $(\mathrm{n}=111)$ acquire information related to health and healthy lifestyle. They could choose several answers. 51 people (45.95\%) get knowledge concerning health and healthy lifestyle in educational institutions, 10 people $(9.01 \%)$ achieve such information at their workplace, 88 people $(79.28 \%)$ get it through the internet, 39 people $(35.14 \%)$ watch TV programs, 9 people $(8.11 \%)$ listen to radio programs. 44 people $(39.64 \%)$ read newspapers, journals, 43 people $(38.74 \%)$ get information from family or relatives, and 52 people $(46.85 \%)$ receive knowledge from friends and acquaintances. The majority of respondents get information through internet, 
from friends and acquaintances, as well as during their studies. As a large number of young adults achieve knowledge during their superlative studies, we should organise more health promotion programs in higher education, which provides facilities to receive knowledge.

In the $10^{\text {th }}$ question I investigated the motivation regarding knowledge acquirement. Respondents $(n=109)$ could choose several answers. 38 persons $(34.86 \%)$ would like to be informed, 40 persons $(36.70 \%)$ would like to change their lifestyle, 77 persons $(70.64 \%)$ try to keep their health status, 46 persons $(42.20 \%)$ want to protect health of their family and loved ones and 2 persons $(1.84 \%)$ have other motivations (surmounting an illness, lifelong learning) to acquire knowledge related to health. They could explain, why it is necessary according to them that individuals acquire knowledge related to health during adult ages. The respondents $(\mathrm{n}=$ 93) could give diverse answers, so I formed 6 categories of them:

a) adaptation to the variable circumstances is possible by enlargement of knowledge,

b) furtherance of the family,

c) healthier, qualitative life,

d) finding a solution of emerging health problems in an individual's life,

e) intellectuality of lifelong learning,

f) for persistence and self-discipline.

According to 47 people (50.54\%) ",adaptation to the variable circumstances is possible by enlargement of knowledge", 12 people (12.9\%) think knowledge acquirement regarding health plays an important role in "furtherance of the family", 33 people's $(35.48 \%)$ aim is "realization of healthier, qualitative life". 2 people $(2.15 \%)$ expect "the solution of emerging health problems their life" by knowledge, 7 people $(7.53 \%)$ think adults must learn in "intellectuality of lifelong learning" and according to 2 people (2.15\%) learning is important in adulthood because "it teaches persistence and self-discipline".

In regard to knowledge acquirement among young people $(\mathrm{n}=109) 55$ persons $(50.46 \%)$ think, that it is very important to be experience-based, 46 persons $(42.20 \%)$ answered it is rather important and 8 persons $(7.34 \%)$ asserted that it is less important. The majority of respondents are motivated relatively to knowledge acquirement, because they would like to keep their health status. Furthermore, according to a large number of people learning in adulthood is important, as we must adapt to the variable circumstances. It is reassuring regarding adult education, as it messages that we have to learn about health in every age. We have to take into consideration that the majority of people emphasise the importance of experience-based approach in knowledge acquirement.

The last question was: „Are you going to participate / would you participate in a program, training or learning form which aims at health education and promotion in near future?" Among respondents 43 people (41.35\%) answered "yes" and 61 people $(58.65 \%)$ wrote "no". They $(\mathrm{n}=33)$ could write in detail in this question. I shape 7 categories of their comments:

a) informative presentation,

b) measurement, consultancy, 
c) training, practical learning form,

d) sport program, sport competition,

e) vocational training,

f) other,

g) whatever regarding the topic.

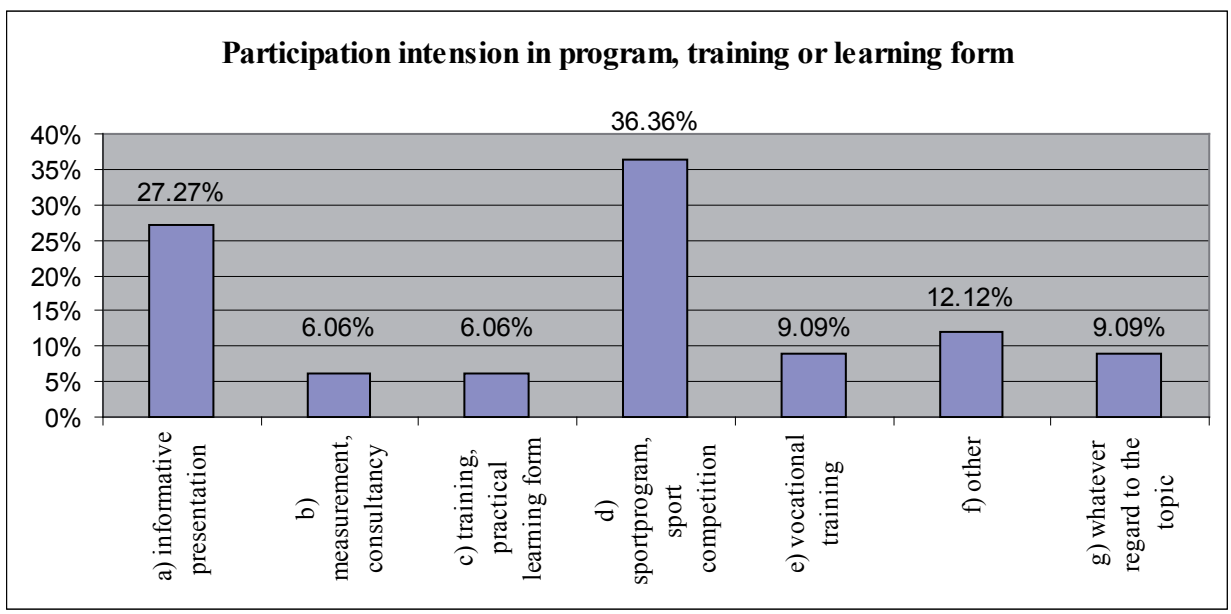

Figure 1. Respondents' participation intension in program, training or learning form Source: Author.

9 persons (27.27\%) would listen to informative presentation, 2 persons $(6.06 \%)$ would participate in measurement, consultancy, 2 people $(6.06 \%)$ are interested in training, practical learning form, 12 people $(36.36 \%)$ would go to sport program, sport competition. 3 people $(9.09 \%)$ are concerned in vocational training, 4 people $(12.12 \%)$ would participate in other programs (e.g. programs of health education at their workplace) and 3 people $(9.09 \%)$ like whatever regarding the topic. A large number of young adults would like to participate in health education and promotion programs in near future. The majority of them would take part in sport programs and informative presentations. This means that in the course of future programs' planning we have to take into account that young adults are interested in communal learning, which is founded on knowledge acquirement and activity.

\section{SUMMARY}

The examined young adults of 18-30 consider health to be a basic, important value. The majority of them marked the highest value: " 8 " , "9", , 10 " on an 1-10 scale in the classification of health's role in their life. In the matter of health promotion the base of learning is that everyone thinks health is a value. Among respondents $(n=111)$ a large number of people (55 persons, $49.55 \%$ of the sample) declared that their health status is goodish. A number of persons assess their health status as excellent, therefore presumably the majority of persons need to 
learn how to improve their health. In regard to young adults' ( $n=109)$ concepts of health, the majority emphasised two components as parts of health; these are: "to have all parts of my body at an operable state" (102 people, 93.58\% of respondents) and "to be spiritually balanced" (102 people, $93.58 \%$ of respondents). Furthermore, many of them enhanced the undermentioned components: „to be with other people in accordance with my social connections" (88 persons, $80.73 \%$ of respondents) and "to be in peace with myself" (80 persons, $73.39 \%$ of respondents). Among respondents $(\mathrm{n}=111) 78$ young people $(70.27 \%)$ answered that they would participate in a sort of learning process related to health. The majority of them, 44 people $(56.41 \%)$ would take part in talking in small groups, 34 people $(43.60 \%)$ would listen to presentation regarding health and 26 people $(33.33 \%)$ would try other playful method. Accordingly, it would be practical to plan such learning programs for young adults, which are founded on communal learning, knowledge acquirement and activity.

Among respondents $(n=67)$ the majority (36 persons, 53.73\%) are interested in nutrition related topics. In the second place, 19 persons $(28.36 \%)$ prefer exercise, sport. In the third place, 17 persons (25.37\%) would deal with the topic of mental health and coping with stress. It can be established in regard to knowledge acquirement related to health of examined young adults $(n=111)$, that the majority (88 people, $79.28 \%$ of sample) achieve information through the internet. In the second place, 52 people $(46.85 \%)$ receive knowledge from friends and acquaintances. In the third place, 51 people (45.95\%) get knowledge related to health and healthy lifestyle in educational institutions. Among respondents $(n=109)$ according to the majority (77 persons, $70.64 \%$ ) the capital motive of knowledge acquirement regarding health is ",to try to keep their health status". In the second place, 46 persons $(42.20 \%)$ want to protect health of their family and loved ones, thereby they collect authentic information. In the third place, 40 persons $(36.70 \%)$ acquire knowledge because they would like to change their lifestyle. 55 respondents $(50.46 \%)(n=109)$ think that experience-based approach is very important in knowledge acquirement. As a large number of young adults get information during their superlative studies, we should organise more health promotion programs in higher education, which provide facilities to receive knowledge and take notice of experience-based aspect.

Among respondents $(n=111)$ the majority (61 persons, $54.96 \%$ of sample) participate in sport program, sport competition, further 20 persons (18.02\%) listen to informative presentation and 17 persons (15.32\%) attend fitness display. A large number of people are interested in programs regarding health, accordingly, presumably they are retractable in further health promotion programs.

In near future 61 respondents $(58.65 \%, \mathrm{n}=104)$ would participate in trainings and programs which aim at health education and health promotion. 33 people explained what kind of programs they are interested in. Among the respondents $(n=33)$ the majority (12 people, $36.36 \%$ ) would go to sport program or competition. In the second place, 9 persons $(27.27 \%)$ would listen to informative presentations. In the third place, 4 people $(12.12 \%)$ would participate in other programs (e.g. programs of health education at their workplace). In the course of future pro- 
grams' planning we have to consider that young adults require communal learning forms, which are founded on knowledge acquirement and activity.

Basing on the results we can conclude that the examined young adults are interested in a number of areas related to health. It can be a starting point form planning health promotion programs.

\section{REFERENCES}

Csíkszentmihályi, M. (1998). And they lived happy ever after. Quality of everydays. Budapest: Kulturtrade Publisher.

Elekes, A. (2006). Health pedagogy. Budapest: Semmelweis University College of Medical.

Feketéné Szakos, É. (2010). Adult learning and education in a new context. Budapest: Akadémiai Kiadó.

Kickbusch, I. S. (2001). Health literacy: adressing the health and education divide. Health Promotion International, 16/3, 289-297.

Kormos, S. (Ed.). (1980). Health education and public education. Budapest: University Press.

Meleg, Cs. (2002). Health education in school: redefinition of the tasks. Hungarian Pedagogy, 102/1, 11-29.

Pikó, B. (2006). Medicine sociology. Budapest: Medicina Publisher Inc.

Szarvasné Mátó, V., \& Benkő, Zs. (2006). A comparative study of college students' understanding of health. Hungarian Pedagogy, 106/2, 107-127.

Szoboszlai, A. (2011). Role of motivation in health education of adults. In: G. Erdei (Ed.), Andragogy and Public education. Old and new challenges for public education in new decade. Adult education, civilization (pp. 204-210). Acta Andragogiae et Culturae, series 23. Debrecen: University of Debrecen Arts of Faculty Institutions of Education Science.

UNESCO Institute for Education. (1999). Health promotion and health education of adults. A series of 29 booklets documenting workshops held at the Fifth International Conference on Adult Education. Retrieved from http://www.unesco.org/education/uie/confintea/pdf/6b.pdf.

World Health Organization. (1946). Constitution. Geneva: Author.

World Health Organization. (1986). Ottawa Charter for Health Promotion. Ottawa: Author.

World Health Organization. (1998). Health Promotion Glossary. Geneva: Author.

Zrinszky, L. (1996). Science of adult education. Introduction to andragogy. Budapest: OKKER. 